05.1

\title{
Расчет прочности прозрачной брони на высокоскоростной удар сферическим поражающим элементом
}

\author{
(ㄱ А.Н. Ищенко, С.А. Афранасьева, Н.Н. Белов, В.В. Буркин, А.С. Дьячковский, К.С. Рогаев, \\ А.Ю. Саммель", Е.Ю. Степанов, А.В. Чупашев, Н.Т. Югов
}

Научно-исследовательский институт прикладной математики и механики Национального исследовательского Томского государственного университета, Томск, Россия

"E-mail: anton_sammel@mail.ru

Поступило в Редакцию 6 августа 2020 г.

В окончательной редакции 17 сентября 2020 г.

Принято к публикации 21 октября 2020 г.

\begin{abstract}
Методом компьютерного моделирования в рамках механики сплошной среды проведен расчет ударного взаимодействия со скоростью $3000 \mathrm{~m} / \mathrm{s}$ стального шарика с мишенью из прозрачной брони (мишень трехслойная). Лицевой слой прозрачной брони выполнен из материала ALON, средний - из закаленного стекла, нижний - из поликарбоната. Исследовалось влияние угла подхода ударника к мишени и толщины слоя из закаленного стекла на процесс пробития мишени.
\end{abstract}

Ключевые слова: прозрачная броня, высокоскоростное взаимодействие, компьютерное моделирование.

DOI: 10.21883/PJTF.2021.03.50572.18500

Назначением прозрачной брони является защита людей, вооружения и военной техники от воздействия поражающих средств (пуль и осколков боеприпасов). Кроме противопульной и противоосколочной стойкости броня должна обладать необходимой прозрачностью и при этом быть как можно легче.

В последнее десятилетие рядом стран проводятся НИОКР по разработке более эффективной прозрачной брони, обладающей при сохранении достигнутого уровня противопульной стойкости меньшей массой и толщиной и базирующейся на принципе построения комбинированной брони с высокотвердым лицевым керамическим слоем. Лицевой слой преграды должен иметь твердость, существенно превышающую твердость материала ударника, а гюгониевский предел упругости должен превосходить таковой для возникающих на начальной стадии ударно-волновых явлений в преграде. Только в этом случае удается обеспечить жесткость преграды, достаточную для разрушения ударника без проникания в преграду.

Перспективным вариантом для создания прозрачных бронепреград высокого класса защиты комбинированного строения может быть использование пластины монокристалла искусственного сапфира (лейкосапфира) толщиной 4-8 mm в качестве лицевого слоя с формированием среднего слоя из силикатного стекла и тыльного из поликарбоната. Использование в качестве лицевого слоя лейкосапфира приводит к снижению массы прозрачной брони. Однако его стоимость очень высока и имеются ограничения в возможности получения лейкосапфиров больших размеров. В США разработан материал ALON (оксинитрид алюминия) [1], который по своим свойствам близок к лейкосапфиру. В [2] описаны технологии синтеза порошков алюмомагниевой шпинели для получения оптически прозрачной керамики и рассмотрены перспективы ее применения в различных областях. Сравнение некоторых физико-механических свойств ALON и других оптически прозрачных материалов (сапфира, шпинели, оксида магния) представлено в [3]. В [4] рассмотрены особенности ударно-волнового деформирования силикатного стекла. Специфической особенностью поведения стекол и, возможно, других высокооднородных хрупких материалов является образование в них волн разрушения при сжатии в области упругого деформирования.

Исчерпывающего описания процессов в волне разрушения в настоящее время нет. Скорость этой волны является дозвуковой и убывает по мере распространения. Волны разрушения представляют собой расширяющуюся сетку пересекающихся трещин, зародившихся на поверхности тела под действием напряжения сжатия.

По-видимому, волны разрушения возможны не только в стекле, но и в других гомогенных хрупких материалах, где дефекты структуры сосредоточены в основном на поверхности тела, в то время как его внутренняя часть свободна от очагов зарождения микротрещины.

В современных расчетах процессов взрыва, высокоскоростного удара и других интенсивных импульсных воздействий реакция материала в каждой точке среды описывается локальными определяющими соотношениями. При таком описании реакция материала полностью определяется набором параметров состояния среды в данной частице и не зависит от соседних частиц. Не вполне ясно, как в такой манере можно описать континуальным образом, например, рост сетки трещин, распространяющихся от частицы к частице. Возможно, рост сетки может быть описан на основе аналогии с диффузионными процессами. 


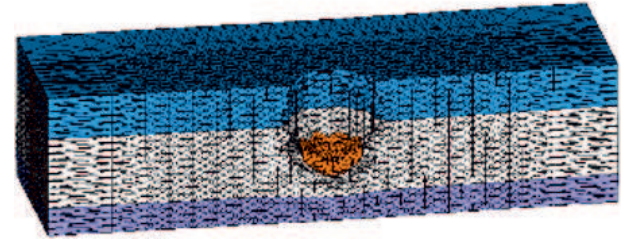

$8 \mu \mathrm{s}$

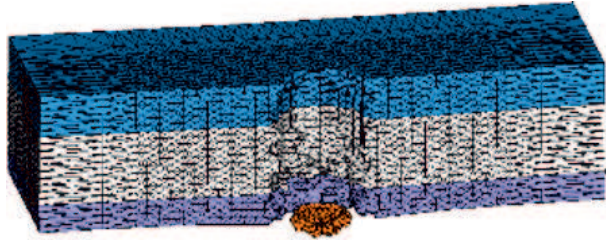

$20 \mu \mathrm{s}$

Рис. 1. Картина пробития сферическим ударником прозрачной мишени толщиной $20 \mathrm{~mm}$.

Экспериментальные ударные адиабаты различных материалов, в том числе корунда, рубина, стекла, оргстекла, представлены в [5]. В [6] приведена ударная адиабата нитрида алюминия, в [7] - ударная адиабата упругого сжатия сапфира. Исследование прочности сапфира при откольном разрушении проведено в [8].

Целью настоящей работы является исследование методом компьютерного моделирования в рамках механики сплошной среды прочности комбинированной прозрачной брони в условиях высокоскоростного удара сферическим поражающим элементом. Математическое моделирование поведения материалов ударника и комбинированной прозрачной брони в условиях высокоскоростного удара проведено в рамках модели пористой упругопластической среды с учетом различных механизмов разрушения [9-14]. Модель реализована в пакете вычислительных программ [15], предназначенном для решения задач удара и взрыва в полной трехмерной постановке, модернизированном для решения динамических задач методом конечных элементов [12].

В рамках изложенной в $[9,14]$ модели поведения конструкционных материалов в условиях высокоскоростного удара проведен расчет ударного взаимодействия стального сферического ударника диаметром $7 \mathrm{~mm}$ со скоростью $3000 \mathrm{~m} / \mathrm{s}$ с двумя типами преград из прозрачной брони толщиной 20 и $24 \mathrm{~mm}$. Начальная масса ударника $1.34 \mathrm{~g}$.

Обе мишени трехслойные. Лицевой слой толщиной $6 \mathrm{~mm}$ выполнен из ALON, нижний толщиной $4 \mathrm{~mm}$ - из поликарбоната. В первой мишени толщина среднего слоя из закаленного стекла $10 \mathrm{~mm}$, во второй мишени толщина среднего слоя $14 \mathrm{~mm}$.

При численном моделировании использовалось уравнение состояния, предложенное Мак-Куином и Маршем [16], в котором за „опорную“ кривую принимается ударная адиабата Гюгонио в виде $D=c_{m 0}+S_{m 0} u$, где $D$ и $u$ - скорость ударной волны и массовая скорость соответственно.

В литературе отсутствуют экспериментальные данные по ударной адиабате Гюгонио для ALON, на основании которых определяются коэффициенты $c_{m 0}$ и $S_{m 0}$ в уравнении состояния. В [17] приведена эмпирическая формула оксинитрида алюминия $(\mathrm{AlN})_{x}\left(\mathrm{Al}_{2} \mathrm{O}_{3}\right)_{1-x}$ в молекулярном соотношении $0.30 \leq x \leq 0.37$, а также указана величина плотности $\rho_{m 0}=3.688 \mathrm{~g} / \mathrm{cm}^{3}$ и его молекулярная масса $56.9877 \mathrm{~g} / \mathrm{mol}$. Используя приведенные данные, ударную адиабату ALON можно определить двумя способами.

Данный материал можно рассматривать как двухкомпонентную среду с начальной плотностью $\rho_{m 0}=v_{1} \rho_{01}+v_{2} \rho_{02}, \quad$ где $\quad v_{i} \quad$ и $\quad \rho_{0 i} \quad(i=1,2) \quad-$ соответственно начальные объемные концентрации и плотности компонентов смеси $\left(v_{1}+v_{2}=1\right)$. Коэффициенты линейной зависимости $c_{m 0}$ и $S_{m 0}$ определяются через ударные адиабаты компонентов смеси $D_{i}=c_{0 i}+S_{0 i} u(i=1,2)$.

Ударная адиабата смеси в переменных, где удельный объем $v_{m}$, давление $p_{m}$ (индекс $m$ относится к матричному материалу), имеет вид

$$
v_{m}\left(p_{m}\right)=\sum_{i=1}^{n} m_{i}\left\{v_{0 i}-\frac{1}{p_{m}}\left[\frac{c_{0 i}}{S_{0 i}} \sqrt{\frac{p_{m} S_{0 i}}{\rho_{0 i} c_{0 i}^{2}}+\frac{1}{4}}-\frac{1}{2}\right]^{2}\right\},
$$

где $m_{i}=v_{i} \frac{\rho_{0 i}}{\rho_{m 0}}-$ массовая концентрация $i$-компоненты $\left(m_{1}+m_{2}=1\right), v_{0 i}=\frac{1}{\rho_{0 i}}$.

Используя для смеси соотношение на ударной волне

$$
D=v_{m 0} \sqrt{\frac{p_{m}}{v_{m 0}-v_{m}\left(p_{m}\right)}}, \quad u=\sqrt{p_{m}\left(v_{m 0}-v_{m}\left(p_{m}\right)\right)}
$$

(где $\left.v_{m 0}=\frac{1}{\rho_{m 0}}\right)$, можно построить зависимость скорости ударной волны от массовой скорости и определить коэффициенты $c_{m 0}$ и $S_{m 0}$.

Когда нет экспериментальных данных, ударные адиабаты химических соединений можно определить по известной начальной плотности и химической формуле [18]:

$$
D=u+3.4\left(\frac{\rho_{m 0}}{M_{e f f}}\right)^{1 / 3} u^{1 / 2}+B\left(\frac{\rho_{m 0}}{M_{e f f}}\right)^{2 / 3},
$$

где $u, D-$ массовая скорость и скорость ударной волны $[\mathrm{km} / \mathrm{s}] ; \rho_{m 0}-$ начальная плотность химических соединений $\left[\mathrm{g} / \mathrm{cm}^{3}\right] ; M_{e f f}=M_{B} / n-$ эффективная молекулярная масса $[\mathrm{g}] ; M_{B}-$ молекулярная масса; $n-$ число атомов в соединении; $B$ - константа, величина которой зависит от группы химических соединений.

Коэффициент Грюнайзена $\gamma_{m 0}$ определяется по формуле $\gamma_{m 0}=\frac{3(1-\mu)}{2(2-3 \mu)}$, где $\mu-$ коэффициент Пуассона. 
Таблица 1. Параметры модели для различных материалов

\begin{tabular}{l|c|c|c|c|c}
\hline Параметр & Сталь & Поликарбонат & ALON & Стекло & Стекло фрагментированное \\
\hline$\rho_{m 0}, \mathrm{~g} / \mathrm{cm}^{3}$ & 7.85 & 1.20 & 3.71 & 2.48 & 2.48 \\
$c_{m 0}, \mathrm{~g} / \mathrm{cm}^{3}$ & 0.457 & 0.174 & 0.74 & 0.31 & 0.16 \\
$S_{m 0}$ & 1.50 & 1.72 & 1.157 & 1.40 & 1.93 \\
$\gamma_{m 0}$ & 2.26 & 2.13 & 1.4648 & $1.29-1.77$ & 3.29 \\
$\mu_{m 0}, \mathrm{GPa}$ & 82.0 & 1.0 & 139 & 33.3 & - \\
$\sigma_{s}, \mathrm{GPa}$ & 1.0 & 0.026 & 12.64 & 7.09 & - \\
$\alpha_{s}, \mathrm{GPa}$ & 0.17 & 0.0173 & 0.7323 & 0.3648 & - \\
$\alpha_{00}$ & 1.0006 & 1.00001 & 1.00001 & 1.00001 & - \\
$\xi^{*}$ & 0.3 & 0.09 & 0.0104 & 0.0104 & - \\
$e_{u}^{*}$ & 1.00 & 0.50 & 0.15 & 0.15 & - \\
$R_{c}, \mathrm{GPa}$ & - & - & 14.15 & 9.0 & - \\
$R_{p}, \mathrm{GPa}$ & - & - & 8.5 & 4.2 & - \\
$T_{c}, \mathrm{GPa}$ & - & - & 6.32 & 3.547 & - \\
$k$ & - & - & 0.75 & 0.75 & - \\
$\sigma_{\max }$ & - & - & 12.64 & 7.09 & \\
$\sigma_{\min }$ & - & - & 0.75 & 0.75 &
\end{tabular}

Примечание. $\rho_{m 0}-$ начальная плотность материала матрицы, $S_{m 0}$ - объемная скорость звука материала матрицы, $c_{m 0}-$ коэффициент линейной зависимости скорости ударной волны от массовой скорости, $\gamma_{m 0}$ - коэффициент Грюнайзена матричного материала, $\mu_{m} 0-$ модуль сдвига материала матрицы, $\sigma_{s}$ - динамический предел текучести материала матрицы, $\alpha_{s}$ - константа материала в уравнении роста пор, $\alpha_{00}-$ остаточная пористость в материале, $\xi^{*}-$ относительный объем пустот, $e_{u}^{*}-$ предельная интенсивность пластической деформации, $R_{c}-$ предел прочности при одноосном сжатии, $R_{p}$ - предел прочности при одноосном растяжении, $T_{c}$ - предел прочности при одноосном чистом сдвиге, $k, \sigma_{\max }, \sigma_{\min }$ - коэффициенты зависимости предела текучести от давления для поврежденного трещинами материала.

Таблица 2. Результаты расчета

\begin{tabular}{|c|c|c|c|c|}
\hline $\begin{array}{c}\text { Угол } \\
\text { встречи, }^{\circ}\end{array}$ & $\begin{array}{c}\text { Остаточная } \\
\text { масса } \\
\text { ударника, } \\
\text { g }\end{array}$ & $\begin{array}{c}\text { Остаточная } \\
\text { скорость } \\
\text { ударника, } \\
\text { m/s }\end{array}$ & $\begin{array}{c}\text { Глубина } \\
\text { кратера в } \\
\text { преграде, } \\
\text { mm }\end{array}$ & $\begin{array}{c}\text { Толщина } \\
\text { преграды, } \\
\text { mm }\end{array}$ \\
\hline 0 & 0.47 & 255 & Пробитие & 20 \\
\hline 30 & 0.31 & 46 & $»$ & 20 \\
\hline 60 & 0.31 & 0 & 8.54 & 20 \\
\hline 70 & 0.45 & 1177 & 5.00 & 20 \\
\hline 0 & 0.44 & 0 & 18.34 & 24 \\
\hline
\end{tabular}

Параметры модели, используемые в расчетах для рассмотренных выше материалов, приведены в табл. 1 .

Результаты математического моделирования представлены на рис. 1-3 и в табл. 2. При фиксированной скорости удара $3000 \mathrm{~m} / \mathrm{s}$ варьировался угол подхода сферического стального ударника к мишени из прозрачной брони.

На рис. 1 в моменты времени 8 и $20 \mu$ s представлены картины проникания ударника в прозрачную мишень. К моменту времени $8 \mu$ s ударник пробивает слой ALON. Распространяющаяся по стеклу ударная волна приводит к разрушению материала под ударником. В последующие моменты времени ударник взаимодействует с разрушенным материалом. К моменту времени $20 \mu \mathrm{s}$ происходит пробитие прозрачной мишени. Масса остатка ударника составляет $0.47 \mathrm{~g}$, он обладает остаточной скоростью $255 \mathrm{~m} / \mathrm{s}$.
Как уже указывалось выше, физико-математическая модель не позволяет рассчитывать волны разрушения в стекле. От поверхности кратера в прозрачной мишени в ударно-сжатый материал могут распространяться трещины, приводящие к дополнительному разрушению в материале. Поэтому материал прозрачной мишени может быть разрушен гораздо сильнее. Трещины могут достичь лицевой поверхности слоя поликарбоната, образуя фрагменты разрушенного стекла. Непробитый слой поликарбоната предохраняет от разлета данных фрагментов.

На рис. 2, $а$ представлены результаты расчета ударного взаимодействия стального шарика с прозрачной мишенью толщиной $20 \mathrm{~mm}$ со скоростью $3000 \mathrm{~m} / \mathrm{s}$ под углом $30^{\circ}$. Угол отсчитывается от нормали к лицевой поверхности мишени.

При данном угле подхода к моменту времени $8 \mu \mathrm{s}$ деформированный ударник пробивает слой ALON и взаимодействует со стеклом. К моменту времени $40 \mu \mathrm{s}$ стальной ударник пробивает слой поликарбоната. В запреградном пространстве масса остатка ударника составляет $0.31 \mathrm{~g}$. Он обладает скоростью $46 \mathrm{~m} / \mathrm{s}$.

На рис. 2, $b$ и $c$ приведены результаты расчета ударного взаимодействия стального ударника с мишенью из бронестекла толщиной $20 \mathrm{~mm}$ со скоростью $3000 \mathrm{~m} / \mathrm{s}$ и углами подхода 60 и $70^{\circ}$ соответственно.

При угле подхода $60^{\circ}$ ударник пробивает слой ALON и останавливается в стеклянном слое. Максимальная глубина кратера $8.54 \mathrm{~mm}$. Масса осколков ударника $0.3 \mathrm{~g}$.

При угле подхода $70^{\circ}$ деформируемый ударник рикошетирует от мишени. Максимальная глубина крате- 


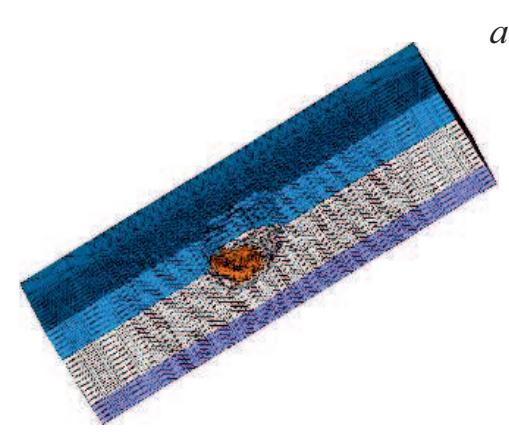

$8 \mu \mathrm{s}$

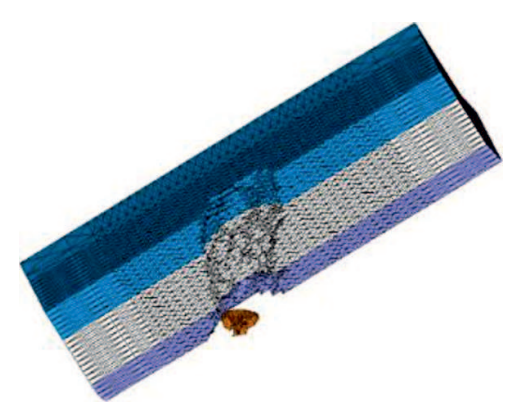

$40 \mu \mathrm{s}$

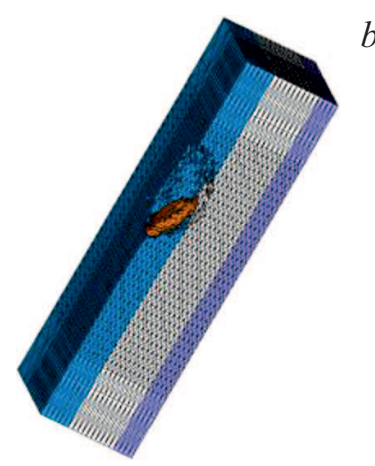

$8 \mu \mathrm{s}$

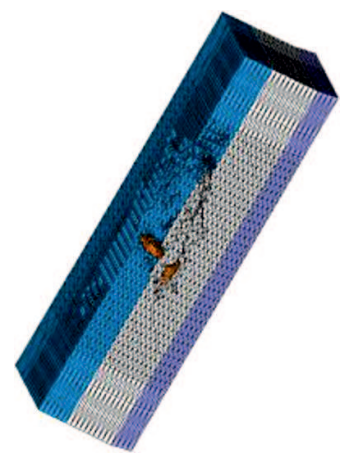

$30 \mu \mathrm{s}$

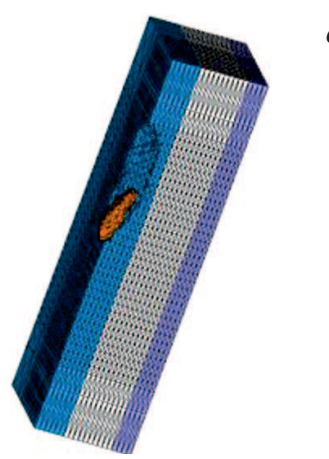

$8 \mu \mathrm{s}$

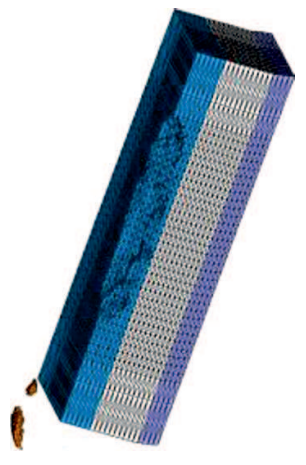

$40 \mu \mathrm{s}$

Рис. 2. Картина пробития сферическим ударником прозрачной мишени толщиной $20 \mathrm{~mm}$ под углом $30(a), 60(b)$ и $70^{\circ}(c)$.

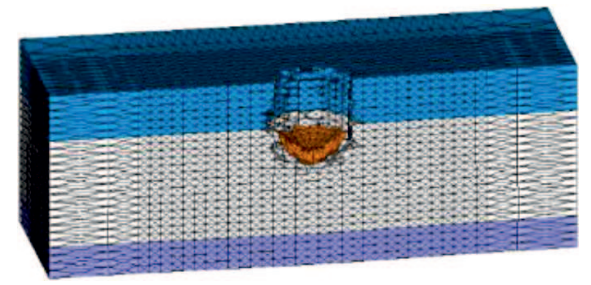

$8 \mu \mathrm{s}$

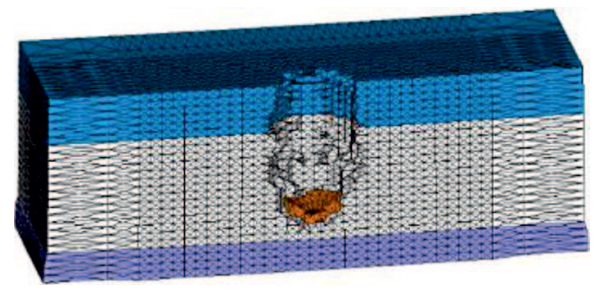

$28 \mu \mathrm{s}$

Рис. 3. Картина взаимодействия сферического ударника с прозрачной мишенью толщиной $24 \mathrm{~mm}$.

ра $5 \mathrm{~mm}$, масса неразрушенных рикошетирующих осколков ударника $0.45 \mathrm{~g}$. Скорость их центра масс $1177 \mathrm{~m} / \mathrm{s}$.

На рис. 3 приведены данные математического моделирования ударного взаимодействия со скоростью $3000 \mathrm{~m} / \mathrm{s}$ стального шарика массой $1.34 \mathrm{~g}$ с прозрачной мишенью толщиной $24 \mathrm{~mm}$. Увеличение толщины стеклянного слоя на $4 \mathrm{~mm}$ привело к тому, что при данной скорости удара мишень сохранила свою целостность. Максимальная глубина кратера составляет $18.34 \mathrm{~mm}$. Массы неразрушенных застрявших осколков ударника $0.44 \mathrm{~g}$.

Таким образом, для данной массы стального шарика и начальной скорости удара оптимальной составной мишенью из прозрачной брони является мишень толщиной $24 \mathrm{~mm}$.

Приведенные данные математического моделирования ударного взаимодействия стального шарика с комби- нированной прозрачной броней показывают, что изложенная в работе модель может быть использована при проектировании защитных конструкций из комбинированной прозрачной брони. Совместное проведение лабораторного эксперимента и математического моделирования, с одной стороны, позволит глубже понять протекающие процессы в прозрачной броне, а с другой уточнить параметры модели.

\section{Финансирование работы}

Исследования проведены в ходе выполнения проекта № 8.2.09.2018 Л Программы повышения конкурентоспособности ТГУ. 


\section{Конфликт интересов}

Авторы заявляют, что у них нет конфликта интересов.

\section{Список литературы}

[1] Transparent aluminum oxynitride and method of manufacture. Patent US4520116A (May 28, 1985).

[2] М.О. Сенина, Д.О. Лемешев, Успехи в химии и хим. технологии, $\mathbf{X X X}$ (7), 101 (2016).

[3] Д.А. Забелин, А.С. Чайникова, Н.Е. Щеголева, Е.С. Игнатьева, Н.В. Голубев, А.А. Качаев, Успехи в химии и хим. технологии, XXXI (3), 31 (2017).

[4] Г.И. Канель, С.В. Разоренов, А.В. Уткин, В.Е. Фортов, Ударно-волновые явления в конденсированных средах (Янус-К, М., 1996).

[5] М.В. Жерноклетов, В.Н. Зубарев, Р.Ф. Трунин, В.Е. Фортов, Экспериментальные данные по ударной сжимаемости и адиабатическому расширению конденсированных веществ при высоких плотностях энергии (Черноголовка, 1996).

[6] Р.Ф. Трунин, Исследование экстремальных состояний конденсированных веществ методом ударных волн. Уравнения Гюгонио (РФЯЦ-ВНИИЭФ, Саров, 2006).

[7] L.M. Barker, R.E. Hollenbach, J. Appl. Phys., 41, 4208 (1970).

[8] А.С. Савиных, Г.И. Канель, С.В. Разоренов, Письма в ЖТФ, 37 (7), 8 (2011).

[9] Н.Н. Белов, В.Н. Демидов, Л.В. Ефремова, А.В. Жуков, А.П. Николаев, В.Г. Симоненко, В.Г. Трушков, М.В. Хабибуллин, И.Е. Шиповский, В.Б. Шуталев, Изв. вузов. Физика, 35 (8), 5 (1992).

[10] С.А. Афанасьева, Н.Н. Белов, В.Ф. Толкачев, М.В. Хабибулин, Н.Т. Югов, ДАН, 368 (4), 474 (1999).

[11] Н.Н. Белов, Н.Т. Югов, А.Н. Табаченко, С.А. Афанасьева, Л.А. Валуйская, А.А. Коняев, Л.С. Марцунова, Изв. вузов. Физика, 45 (8), 54 (2002).

[12] Н.Н. Белов, Н.Т. Югов, Д.Г. Копаница, А.А. Югов, Динамика высокоскоростного удара и сопутствующие физические явления (STT, Northampton-Томск, 2005).

[13] Н.Н. Белов, О.В. Кабанцев, Д.Г. Копаница, Н.Т. Югов, Расчетно-экспериментальный метод анализа динамической прочности элементов железобетонных конструкиий (STT, Томск, 2008).

[14] С.А. Афанасьева, Н.Н. Белов, Ю.А. Бирюков, В.В. Буркин, А.Н. Ищенко, В.3. Касимов, А.Н. Табаченко, Н.Т. Югов, Композищионные материалы: разработка, динамические испытания, математическое моделирование (Изд-во НТЛ, Томск, 2016).

[15] Н.Т. Югов, Н.Н. Белов, А.А. Югов, Расчет адиабатических нестационарных течений в трехмерной постановке (РАНЕТ-3). Свидетельство о государственной регистрации программ для ЭВМ № 2010611042 (Федеральная служба по интеллектуальной собственности, патентам и товарным знакам, М., 2010).

[16] Р.Г. Мак-Куин, С.П. Марш, Дж.В. Тейлор, Дж.Н. Фритц, У. Картер, в кн. Высокоскоростные ударные явления (Мир, М., 1973), с. 299-427.

[17] https://ru.wikipedia.org/wiki/Оксинитрид_алюминия

[18] В.Ф. Анисичкин, Физика горения и взрыва, № 5, 151 (1980). 